\title{
Being Dissimilar: Religious Dissimilarity, Gender Dissimilarity, Value Dissimilarity and Job Satisfaction
}

\author{
*Irfan Ullah, Muhammad Usman, Abdus Sattar Niazi, Muhammad Farooq, Waheed Afzal, \\ Muhammad Asif Khan \\ Iqra University, Islamabad, Pakistan \\ *irfanullahtarar1979@gmail.com
}

\begin{abstract}
The aim of this research is to study the impact of religious dissimilarity, and gender dissimilarity on job satisfaction. Religious dissimilarity and sexual dissimilarity definitely exaggerated supposed value dissimilarity, which in line, detained a pessimistic relationship with job satisfaction. These properties are capable, though, by a considerable religious difference, religious personal identity relations such that, for people whose religious values are a vital element of who they are, becoming religiously dissimilar in the place of work robustly impact their supposed value dissimilarity.
\end{abstract}

\section{Keywords: Religious Identity, Identification, Job satisfaction}

\section{Introduction}

Increase in organizational diversity means that at present, individuals are probable to effort with, effort for, or control somebody who is dissimilar from the identity. These dissimilarities are vital, because dissimilar individuals have been revealed to contain a smaller amount psychosomatic affection to their business (Tsui, O’Reilly, \& Egan, 1992). They articulate a smaller amount of contentment with their work (Mueller, Iverson, Finley \& Price, 1999). Chattopadhyay (1999) exclaims that individuals who are dissimilar from the self, comparative to those who are not, connect in less citizenship behaviors. Wesolowski and Mossholder (1997) recognize that those individuals are not managed literally. Behaviours and attitudes of supervisors towards their employees are also exaggerated by relationships among the groups, as greater dissimilarities are related with inferior results for the employee (Judge \& Ferris, 1993). Researchers have considered touching further than demographic difference, such as surface-level dissimilarity, to as well reflect on the belongings of more essential, deep-level character, for example attitude and behavior (Riordan, 2000). Hobman, Bordia and Gallois (2003) exclaim that deeplevel dissimilarity is considered to manipulate a vital function as they are linked with demographic character. It is also considered supplementary proximal predecessor of succeeding behavioral and attitudinal effects (Harrison, Price, Gavin \& Florey, 2002). Deep-level difference arbitrates the correlation between surface level dissimilarity (equally tangible and intangible) and together sentimental (assistant fulfillment) and behavioral (for example turnover intention) effects.

Conjointly, this studying indicates to the dominance of bottom-level dissimilarities in forecasting the outcomes of diversity (Cunningham 2006a, 2007b). The rationale of the present research is to broaden the assessment of bottom-level dissimilarities by taking into account the impact of religious dissimilarity and sexual dissimilarity from other individuals in grouping. Religion has happened to a progressively more important element of the place of work. Study probing the property of religious and sexual dissimilarity in the firms' perspective is not sufficient. If the particular grounds of guidance and administration researches have evaded religion, the educational authority of religious researches has ignored the place of work (Hicks, 2003). Likewise, extraordinarily lacking is study, which has been executed on religion in the place of work (Moore, 2008). This exclusion is adverse while taking into account that religious values preserve an essential aspect of one's self (Markus, 1977). Study argues that religious dissimilarity and sexual dissimilarity are associated with supposed value dissimilarity, which in line, pessimistically influences job satisfaction. These effects may be supplementary increased by personal religious identity of the individual, or the scope to which his spiritual belief is a vital component of which he is an individual.

\section{Literature Review}

The societal classification approach is vital in order to recognize the effects of difference (Riordan, 2000). So it is engaged as a hypothetical lens in the present study. From this angle, which together illustrates 
from societal identity speculation (Tajfel \& Turner, 1979) and self-classification speculation (Turner, Hogg, Oakes, Reicher, \& Wetherell, 1987)-individuals classify others and themselves into different groupings. The classification process may be established on the base of a heap of characteristics, counting beliefs, attitudes, demographics, or other factors, for instance religion. Consequently, groups describe themselves in expressions of a societal identity. The individuals, who are like to the identity, are regarded as in-group members whereas the individuals who are dissimilar are regarded out-group people. Ingroup people, comparative to out-group people, are wished more, given superior reliance, and are considered as the receivers of additional affirmative behaviors (Gaertner, Mann, Murrell, \& Dovidio, 1989). Accordingly, the classification process frequently consequences in perceptual unfairness between out-groups and in-groups with "them" and "us" dynamics existing.

\section{Figure 1: Theoretical Framework}

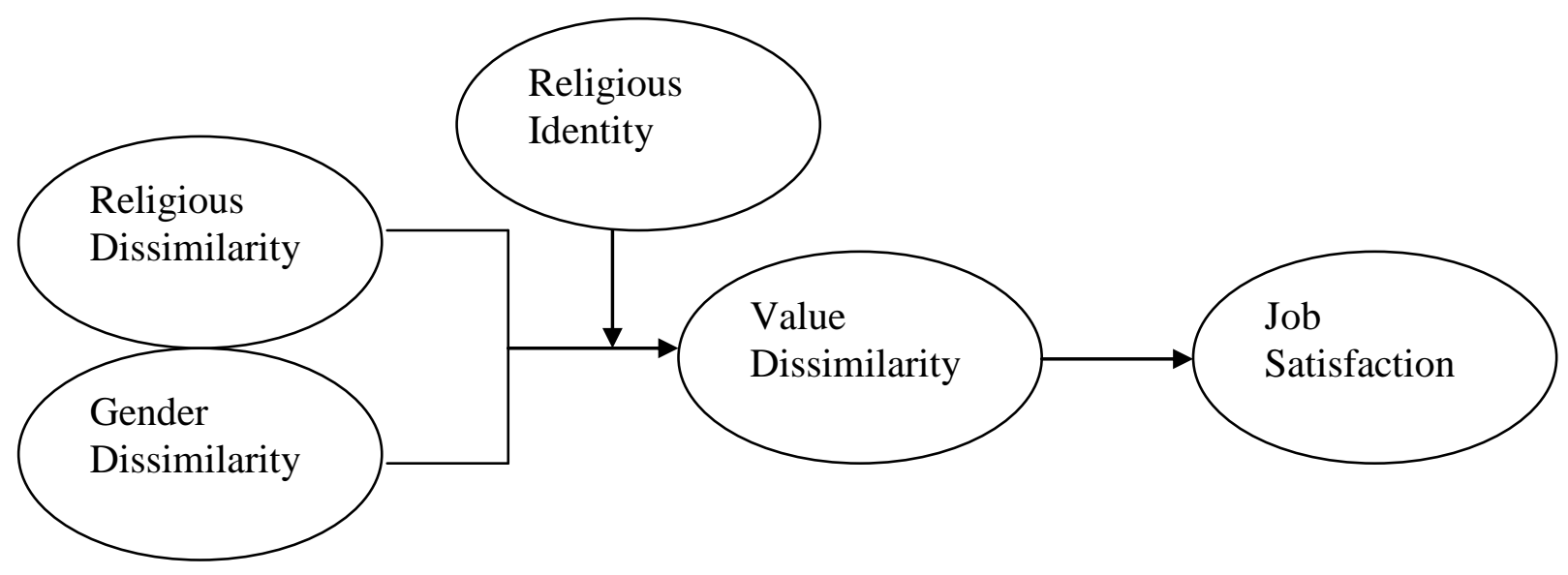

The societal classification outline has directed a lot of the diversity study. The same as van Knippenberg, De Drue and Homan (2004) composed that the associates of a group are more optimistically prone towards their group and the individuals inside it if colleagues are similar instead of different to the identity. Generally, a comparable model was projected there. Namely, individuals who vary in the business were projected to comprise a smaller amount of job satisfaction than those were their complements. Somewhere this research is different from previous study (Hobman et al., 2003; Harrison et al., 2002; Cunningham, 2006a, 2007b) is the concern of a more extensive range of deep level distinctiveness-explicitly by stirring ahead of consideration focused only on attitudinal and behavioral dissimilarities to also regard as the effects of religion.

Perceived religious dissimilarity: Since before observed, assessment of religion in the place of work is deficient (Hicks, 2003). This is an unsatisfactory lapse taking into consideration that more than $80 \%$ of the individuals in this universe tend to adopt one of the five major religions of the world: Hinduism, Islam, Budhism, Christianity and Judaism (Kriger \& Seng, 2005), thus signifying that the religion exaggerates the greater part of individuals in a little mode. The scholars have revealed that persons exercise religion as a means to classify the others and individuality (Weeks \& Vincent, 2007). Hicks (2003) reveal that the belongings of spirituality and religious conviction are also observed in the place of work. The augmented occasion exhausted away from residence and family, attached with more period exhausted at job, consequences in individuals in search of greater connotation in their biographies - a pursuit that repeatedly directs to a better incorporation of spiritual and job characteristics (Jurkiewicz \& Giacalone, 2004; Cash \& Gray, 2000; Kelly, 2008). Hence, people are now a days probable to amalgamate their spiritual values and characteristics into the job. Finally, religious values have been revealed to persuade an array of job conclusions, for instance management approach (Kriger \& Seng, 2005; Hicks, 2002; Fry, 2003; Whittington, Pitts, Kageler, \& Goodwin, 2005), moral behavior (Weaver \& Agle, 2002), and tactical resolutions prepared (Shafran, 2002; Dunn \& Stevenson, 1998). Religion influences different phases of the life of an individual, and religion has developed into progressively more prominent in the place of work.

Therefore, assessment of the impact of religious difference-a bit so as has not been strained-is defensible. Individuals are probable to exercise their spiritual values to classify others and themselves into out-group members and in-group members (Weeks \& Vincent, 2007). Definitely, religion has been 
integrand-in conjunction with sex, nationality and society-among the foundation societal types around which a person's societal identity is structured (Burris and Jackson, 2000). Because an outcome of this classification, the dissimilar people in their place of work may be observed by other individuals as outgroups, and therefore they are probable to believe themselves the same as spiritual minorities within that circumstance. The individual who comprehends himself to be devotedly dissimilar in the place of work might consider that his ethics differ consequently (Robbins \& Judge, 2007). This perception is reliable with the perception of Chattopadhyay (1999). He indicated that individuals utilize relational similarities and differences to formulate supplementary illations about the principles of others. Diverse religious appellations differ on a variety of characteristics, for instance their sentiments in the direction of the life after death, the atmosphere, the demise consequence, sexual direction, and the role of adult females in culture. These dissimilarities reveal a deviation in what individuals embrace precious and significant to them-that is, what they rate. Therefore, the individual who varies as compared to others in the place of work according to his spiritual values is also prone to differ in his beliefs. Thus, we can hypothesize:

\section{Hypothesis 1: Perceived religious dissimilarity have impact on perceived value dissimilarity.}

Gender Dissimilarity: Favoritisms, societal customs and institutional restraints can create dissimilarities in workforce position transversely pair variety. Numerous origins account proof of work inequity founded on sexual point of reference (Levine and Leonard 1984; Levine 1979; Weichselbaumer, 2003; Empire State Pride Agenda 2001; Colvin 2004). Because gender dissimilarity influences whether a person is employed or dismissed, job position can be influenced also. Salary inequity can influence job loss ultimately. Flanagan (1978) describes that minor salaries acknowledged by gay man decrease the shade cost of his moment in time; therefore, he would exercise more time-intensive exploration schemes, which would tend to enhance the likelihood of joblessness. A number of lesbians and gays search for employment positions fewer probable to picture them to Economical (2009) inequity and irritation (Levine 1979; Levine and Leonard 1984; Klawitter and Flatt, 1998). Putting limitations on suitable employment, together with inequity in engaging exercises, enhances the projected duration of exploration and more enhances the possibility of joblessness.

The Laws, which prohibit employment inequity founded on sexual discrimination, may tend to decrease or increase unemployment of lesbians and gay men. If there is a country law indicative of a more liberal environment towards lesbians and gays, joblessness for similar gender allies could be lesser. The laws, which are Anti-discrimination, are also probable to enhance the unemployment of groups who are in minority (Gilman, 1965). Anti-discrimination laws are capable to attract a huge figure of lesbians and gays, and to hire them all, there may not be ample non-discriminatory employers. Employers having a well-built dislike for employing lesbians and gays will tend to appoint them only at low wages for that dislike. Remuneration may not decrease low enough, due to reasons for instance, minimum wage laws, anti-discrimination laws or high reservation wages of employees; in that box biased company would relatively appoint a heterosexual rather than a gay or lesbian individual. Discrimination tends to make employment more complicated to locate, thus some gays and lesbians may tend to turn into depressed, and give up the workforce. Societal customs and lesser salaries of womanhoods raise the probability female with male mates will depart the workforce to focus in home making (Blau et al. 2006). Leppel (2007) exclaims that officially authorized relationship increases the estimated time-span of the affiliation (and make specialty more probable for the couples who are married.

The impact of children on workforce position may also tend to vary with pair kind. Without woman partner to undertake the customary task of housewife, a gentleman same-sex co-worker who performs as prime care-provider would be less probable to contribute in the workforce (Tebaldi and Elmslie, 2006). Giddings (2003) reveals that the overturn is applicable to family units who have two female co-workers. Institutional restraints, for instance the lack of job security, family business benefits and authorized wedding, supplementary decrease the likelihood of lesbians being full-time homemakers. Considering all these aspects, we can hypothesize as:

Hypothesis 2: Sexual dissimilarity has positive impact on value dissimilarity.

Religious personal identity: Religious beliefs can have an effect on persons in a different way. For some people, such strong beliefs are a center element of who they are whereas for many others, they may consider slight about their spiritual values excepting as plainly provoked to accomplish thus. Here in both faces, persons who grasp a special position of spiritual values; this is the power of the values and how 
they are essential to individual's discernment of the identity that varies. This changeability underlines the significance of spiritual individual identity, or the intensity of significance located on the religion of an individual (Ladd, 2007; Becker \& Hofmeister, 2001; Markus, 1977). Personal identity is an identity a person grasps which is supposed as important to her or his self-concept (Brewer, 1991). It signifies a vital element of personality of a person. It also plays a significant part in how individuals consider regarding themselves (Randel \& Jaussi, 2003; Cunningham, Choi, \& Sagas, 2008; Luhtanen \& Crocker, 1992). Personal identity is the individuated identity - that distinctiveness which discriminates one person from others in a societal framework (Brewer, 1991).

Religious personal identity of a person is principally significant in the perspective of debates associated with difference. It is likely to depict from associated researches for revealing these effects. Randel and Jaussi (2003), for example, observed the impacts of practical diversity (dissimilarity in employees' practical part of skill in the business) on consequent concert. The scholars originated that among individuals who were considered in the practical marginal, individuals with strength of useful individual identity executed more disappointingly than carried out those who did not embrace an individual distinctiveness like this. Cunningham et al. (2008) examined the impacts of ethnic difference among people of healthy groups. These researchers established that the ethnic minority individuals were considered more probable to be recognized as ethnically dissimilar in the cluster. Simultaneously, this study recommends that personal identity of forms how a person understands being dissimilar and whether or not individuals place reserve into those dissimilarities.

In illustration from the text, it was anticipated that religious personal identity would be likely to force the effect of becoming faithfully dissimilar. For citizens who embrace a sturdy spiritual individual personality, the effects of becoming religiously dissimilar are probable to be definite, and the correlation involving supposed religious difference and value difference well built. In contrast, if spiritual personal identity is small, then it will subject small whether an individual is dissimilar or similar, established on that attribute. The correlation between religious dissimilarity and consequent results may be feeble, in this box. Collectively, the hypothetical support and pragmatic outcomes advocate that personal identity probable lead the associations among difference from others in the cluster and succeeding results. Hence, it was hypothesized:

Hypothesis 3: Religious personal identity has a moderate impact on the correlation between religious dissimilarity-sexual dissimilarity and perceived value dissimilarity.

Value dissimilarity and job satisfaction: The impact of value dissimilarity on job satisfaction was also observed in several studies. This conclusion was selected for numerous grounds. First, from a HRM side, perceptive elements that contour how much people benefit from their job are of vital substance. Regard as, for example, job satisfaction has been related with worker proficiency (Judge, Thoresen, Bono, \& Patton, 2001), well-being and health (Johns \& Saks, 2001), and extra-ordinary behaviors (Johns \& Saks, 2001). The second ground is that several researches have designated that demographic difference is unconstructively associated to satisfaction (Mueller et al., 1999; Cunningham, 2006a), although assessments linked to the impacts of religious difference are deficient. When groups consider themselves dissimilar on bottom-level distinctiveness, for instance ethics, they are also probable to comprise meager job understandings (van Knippenberg et al., 2004). For example, individuals who consider themselves different on bottom-level characters are less probable to generally incorporate into the grouping (Moore, 2008; Harrison et al., 2002), articulate a lesser amount of satisfaction with partners (Cunningham, 2007b), and exchange a few words of their objectives to leave the organization (Cunningham, 2007b). These relations are probable a role of societal classification method and the out-group position in which an individual is located when possessing dissimilar ethics as compared to others. Accordingly, we can hypothesize:

\section{Hypothesis 4: Perceived value dissimilarity have a negative relationship with job satisfaction.}

\section{Discussion}

Although workplace diversity has acknowledged extensive consideration, assessment of religion in the place of work has mainly been wanting (Moore, 2008; Hicks, 2003). This adverse lapse indicates that the majority of people of the earth follow a spiritual faith (Kriger \& Seng, 2005). Inhabitants are progressively developing spiritual \& religious values a significant element of their job (Jurkiewicz \& Giacalone, 2004; 
Cash \& Gray, 2000; Kelly, 2008). The rationale of this research is to broaden the diversity text, taking into consideration the relations among religious personal identity, religious dissimilarity, sexual dissimilarity, value dissimilarity, and job satisfaction. Outcomes signify that religious personal identity and religious dissimilarity were pessimistically related with each other. Therefore, as an individual measures himself to be more devotedly comparable to his work fellows, his spiritual individual distinctiveness is also enlarged. This prototype is divergent to what may be estimated from a societal classification side, as becoming dissimilar should increase the strikingness of that identity set, instead of the reverse prototype (Cunningham et al., 2008). Shared reality theory can be utilized to explicate these results (Hardin \& Higgins, 1996; Hardin \& Conley, 2001). Seeing this angle, people embrace a definite identity, since others in their existence, allocate those self-views. The attainment of mutual realism hence provides the double function of constructing both entity values and societal relations. Functional to the present research, if majority of the work fellows share their spiritual sights, then the amount to which those sights are an innermost element of the identity may be increased.

This is probable to principally be the box in the present perspective, because intercollegiate exercise has been described like an extremely spiritual location (Cunningham, 2007a). Some other researches like Magee \& Hardin have originated support that mutual realism procedures are related with religiousism. That is a region, which has not been studied more, and it needs further study. Consistent with the research theory, religious difference was consistently interrelated to perceived value dissimilarity that in line was depressingly linked with job satisfaction. The earlier relationship was experienced by religious dissimilarity $\mathrm{x}$ religious personal identity interface. For persons whose spiritual thinking was an essential element of who they were as a human, existing devotedly different as compared to others robustly forecasted the perceived value difference. Slighter things were originated for groups who had a small amount of religious personal identity. These results emphasize the significance of taking into consideration the personal identity in the research of how difference persuades succeeding results. Considering one side, the identification of religious personal identity has mostly been restricted to the external framework of job, for instance assessment of religious attachment (Becker \& Hofmeister, 2001) or decease behaviours (Ladd, 2007), to give surname a handful (Moore, 2008). The research donates to the text by signifying that religious personal identity donates to the views of the identity-relation that a person has with others. From a dissimilar side, numerous researchers have regretted the excessively onedimensional access to a large extent of the diversity investigation (Lawrence, 1997; van Knippenberg et al., 2004; Chattopadhyay, Tluchowska, \& George, 2004).

The letdown to regard as important moderating or intervening variables, together with the deficient in of linkage to the primary belief of assumption, can potentially consequence in deceptive results and underestimate effects. Such was obviously demonstrated, as a focal point exclusively on spiritual difference would have ensued in the invalid ending that becoming dissimilar influences the entire groups the same. This is not the cage, because the sound effects of being religiously dissimilar from other people was different established on the base of religious personal identity. Consequently, expressing and checking an important moderating manipulate in this phase, counting religious personal identity, aided to drop illumination on the influence of religious dissimilarity. Finally, value dissimilarity was observed as a momentous forecaster of job satisfaction. It is reality that value dissimilarity detained the firmest relationship among all other variables with job satisfaction. These results are reliable with prior study demonstrating the pessimistic impacts of containing dissimilar morals from the colleagues of a person (Harrison et al., 2002; Cunningham, 2006a, 2007b; Moore, 2008). These results have also been pragmatic among grouping, where value mixture donates to the exciting inconsistency of a group (Barsade, Ward, Turner, \& Sonnenfeld, 2000), whereas it is pessimistic from its efficiency and effectiveness (Jehn, Northcraft, \& Neale, 1999).

\section{Managerial Implications}

These results have some suggestions. Religious dissimilarity forecasted views of value difference and eventually lesser job satisfaction is disturbing (Hicks, 2003; Kelly, 2008). Cash and Gray (2000) expressed an outline, which might be utilized to put up spiritual desires in the place of work. Obviously, reliable, reasonable, and lawful adjustments of spiritual and religious desires are required. Maybe more substantively, yet, is the demand for individuals to consider esteemed in the place of work, regardless of their religious values. There respites the significance of a company's diversity approaches. When dissimilarities among groups are observed as possessions to the company, while there is a hub on perceptive the approach in which individuals differ, when there is an understanding that labor force 
diversity can get constructive results to the firm, and when there is a considerate of how to comprehend assumed remuneration, then groups who might vary from the distinctive bulk are probable to contain affirmative understandings in that framework (van Knippenberg \& Schippers, 2007; Ely \& Thomas, 2001; Hicks, 2003). Certainly, van Knippenberg, Haslam, and Platow (2007) originated that, among people, where diversity was observed as causal to team executing, sexual mixture was positively connected with group recognition. The same things might be anticipated in the present framework in this way that religiously dissimilar groups from others in the firm might have constructive understandings at what time the dissimilarities like these, were esteemed and assumed to be a donor to the victory of the business. Previous study has revealed that incorporation of diversity into the firm's vision, structure and values, senior administration support, and training \& development are all vital in building an atmosphere like this (Holvino, Ferdman, \& Merrill-Sands, 2004; Gilbert \& Ivancevich, 2000).

\section{Limitations and Direction for Future Research}

In spite of the strength, the research has a few limitations. First, the data were accumulated on conceptual basis. Moreover, someone may have a question about the exploit of single-point events to evaluate dissimilarity. In addition, real religious dissimilarities were not appraised, because managers were not inquired to reveal their religious attachment. Prospect scholars are advised to reflect on this likelihood. The outcomes of the research also give queries that should be tackled in upcoming study. For example, whereas this research donated to the text by taking into consideration the impact of religious difference, some other bottom-level dissimilarities may also influence the attitudes and behaviours of people in the place of work. Careless, similar results might be anticipated, as gender personal identity might interrelate to forecast succeeding results. Upcoming study is required to observe these livelihoods. From a diverse side, study implemented a societal classification scheme to observe the impact of religious dissimilarity; though, study did not explore issues, which may persuade the salience of societal classifications, for example fit, convenience, and mental openness. It is possible that the projecting capability of the model would develop with these factors incorporated. Lastly, in order with the suggestion for exercise, future scholars are advised to study the amount to which constructive diversity mentalities might improve the prospective pessimistic impact of being religiously dissimilar in the place of work. Certainly, specified the religious diversity of the labor force, discovering ways to decrease the pessimistic effects of being dissimilar from others is vital.

\section{References}

Barsade, S. G., Ward, A. J., Turner, J. D. F. \& Sonnenfeld, J. A. (2000). To your heart's content: A model of affective diversity in top management teams. Administrative Science Quarterly, 45, 802-836.

Becker, P. E. \& Hofmeister, H. (2001). Work, family, and religious involvement for men and women. Journal for the Scientific Study of Religion, 40, 707-722.

Blau, F. D., Ferber, M. A. \& Winkler, A. E. (2006). The Economics of Women, Men and Work, 5th ed. Upper Saddle River, NJ: Pearson Prentice Hall.

Brewer, M. B. (1991). The social self: On being the same and different at the same time. Personality and Social Psychology Bulletin, 17, 475-482.

Burris, C. T. \& Jackson, L. M. (2000). Social identity and the true believer: Responses to threatened selfstereotypes among the intrinsically religious. British Journal of Social Psychology, 39, 257-278.

Cash, K. C. \& Gray, G. R. (2000). A framework for accommodating religion and spirituality in the workplace. Academy of Management Executive, 14(3), 124-133.

Chattopadhyay, P. (1999). Beyond direct and symmetrical effects: The influence of demographic dissimilarity on organizational citizenship behavior. Academy of Management Journal, 42, 273287.

Chattopadhyay, P., Tluchowska, M. \& George, E. (2004). Identifying the in-group: A closer look at the influence of demographic dissimilarity on employee social identity. Academy of Management Review, 29, 180-202.

Colvin, R. (2004). The extent of sexual orientation discrimination in Topeka, Kansas. National Gay and Lesbian Task Force Policy Institute. Accessed on 4 August 2005 from http://www.thetaskforce.org/ downloads/TopekaDiscrimination.pdf

Cunningham, G. B. (2006a). The influence of demographic dissimilarity on affective reactions to physical activity classes. Journal of Sport and Exercise Psychology, 28, 127-142.

Cunningham, G. B. (2007b). Perceptions as reality: The influence of actual and perceived demographic dissimilarity. Journal of Business and Psychology, 22, 79-89. 
Cunningham, G. B., Choi, J. H. \& Sagas, M. (2008). Personal identity and perceived dissimilarity among college athletes. Group Dynamics: Theory, Research \& Practice, 12, 167-177.

Dunn, R. \& Stevenson, C. (1998). The paradox of the church hockey league. International Review for the Sociology of Sport, 32, 131-141.

Ely, R. J. \& Thomas, D. A. (2001). Cultural diversity at work: The effects of diversity perspectives on work group processes and outcomes. Administrative Science Quarterly, 46, 229-273.

Empire State Pride Agenda. (2001). Anti-gay/lesbian discrimination in New York State: analysis of a statewide survey conducted by the Empire State Pride Agenda. Accessed on 14 August 2005 from http:// www.prideagenda.org/pride/survey.pdf

Flanagan, R. J. (1978). Discrimination theory, labor turnover, and racial unemployment differentials. Journal of Human Resources, 13, 187-207.

Fry, L. W. (2003). Toward a theory of spiritual leadership. The Leadership Quarterly, 14, 693-727.

Gaertner, S. L., Mann, J., Murrell, A. \& Dovidio, J. F. (1989). Reducing intergroup bias: The benefits of recategorization. Journal of Personality and Social Psychology, 57, 239-249.

Giddings, L. (2003). But ... who mows the lawn? The division of labor in same-sex households. In Karine S. Moe (ed.), Women, Family, and Work: Writings on the Economics of Gender. Oxford: Blackwell, 85-102.

Gilbert, J. A. \& Ivancevich, J. M. (2000). Valuing diversity: A tale of two organizations. Academy of Management Executive, 14(1), 93-105.

Gilman, H. J. (1965). Economic discrimination and unemployment. American Economic Review, 55, 107796.

Hardin, C. D. \& Conley, T. D. (2001). A relational approach to cognition: Shared experience and relationship affirmation in social cognition. In G. B. Moskowitz (Ed.), Cognitive social psychology: The Princeton symposium on the legacy and future of social cognition (3-17). Mahwah, NJ: Lawrence Erlbaum.

Hardin, C. D. \& Higgins, E. T. (1996). Shared reality: How social verification makes the subjective objective. In R. Sorrentino \& E. T. Higgins (Eds.), Handbook of motivation and cognition, 3, 28-84. New York: Guilford Press.

Harrison, D. A., Price, K. H., Gavin, J. H. \& Florey, A. T. (2002). Time, teams, and task performance: Changing effects of surface- and deep-level diversity on group functioning. Academy of Management Journal, 45, 1029-1045.

Hicks, D. A. (2003). Religion and the workplace: Pluralism, spirituality, leadership. New York: Cambridge University Press.

Hicks, D. A. (2002). Spiritual and religious diversity in the workplace: Implications for leadership. The Leadership Quarterly, 13, 379-396.

Hobman, E. V., Bordia, P. \& Gallois, C. (2003). Consequences of feeling dissimilar from others in a work team. Journal of Business and Psychology, 17, 301-325.

Holvino, E., Ferdman, B. M. \& Merrill-Sands, D. (2004). Creating and sustaining diversity and inclusion in organizations: Strategies and approaches. In M. S. Stockdale \& F. J. Crosby (Eds.), the psychology and management of workplace diversity (245-276). Malden, MA: Blackwell.

Jehn, K. A., Northcraft, G. B. \& Neale, M. A. (1999). Why differences make a difference: A field study of diversity, conflict, and performance in workgroups. Administrative Science Quarterly, 44, 741763.

Johns, G. \& Saks, A. M. (2001). Organizational behavior: Understanding and managing life at work. Toronto, ON: Addison Wesley Longman.

Judge, T. A., Thoresen, C. J., Bono, J. E. \& Patton, G. K. (2001). The job-satisfaction-job performance relationship: A qualitative and quantitative review. Psychological Bulletin, 127, 376-407.

Judge, T. A. \& Ferris, G. R. (1993). Social context of performance evaluation decisions. Academy of Management Journal, 36, 80-105.

Jurkiewicz, C. L. \& Giacalone, R. A. (2004). A values framework for measuring the impact of workplace spirituality on organizational performance. Journal of Business Ethics, 49, 129-142.

Kelly, E. P. (2008). Accommodating religious expression in the workplace. Employee Responsibilities and Rights Journal, 20, 45-56.

Klawitter, M. M. \& Flatt, V. (1998). The effects of state and local antidiscrimination policies for gays and lesbians. Journal of Policy Analysis and Management, 17, 658-86.

Kriger, M. \& Seng, Y. (2005). Leadership with inner meaning: A contingency theory of leadership based on the worldviews of five religions. The Leadership Quarterly, 16, 771-806.

Ladd, K. L. (2007). Religiosity, the need for structure, death attitudes, and funeral preferences. Mental Health, Religion, \& Culture, 10, 451-472. 
Lawrence, B. S. (1997). The black box of organizational demography. Organization Science, 8, 1-22.

Leppel, K. (2007). Homeownership among opposite- and same-sex couples in the US. Feminist Economics, $13,1-30$.

Levine, M. P. (1979). Employment discrimination against gay men. International Review of Modern Sociology, 9, 151-63.

Levine, M. P. \& Leonard, R. (1984). Discrimination against lesbians in the work force. Signs, 9, 700-10.

Luhtanen, R. \& Crocker, J. (1992). A collective self-esteem scale: Self-evaluation of one's social identity. Personality and Social Psychology Bulletin, 18, 302-318.

Markus, H. (1977). Self-schemata and processing information about the self. Journal of Personality and Social Psychology, 35, 63-78.

Moore, T. W. (2008). Do perceived differences in religion matter at work? Culture and Religion, 9, 267286.

Mueller, C. W., Finley, A., Iverson, R. D. \& Price, J. L. (1999). The effects of group racial composition on job satisfaction, organizational commitment, and career commitment. Work and Occupations, 26, 187-219.

Randel, A. E. \& Jaussi, K. S. (2003). Functional background identity, diversity, and individual performance in cross-functional teams. Academy of Management Journal, 46, 763-774.

Riordan, C. M. (2000). Relational demography within groups: Past developments, contradictions, and new directions. In G. R. Ferris (Ed.). Research in personnel and human resources management, 19, 131173. Greenwich, CT: JAI Press.

Robbins, S. P. \& Judge, T. A. (2007). Organizational behavior (12th ed.). Upper Saddle River, NJ: Prentice Hall.

Shafran, A. (2002). Mr. Feuerstein is a legend in the corporate world: His company is now bankrupt and he does not regret a thing. Aish.com. Retrieved February 6, 2006.

Tajfel, H. \& Turner, J. C. (1979). An integrative theory of intergroup conflict. In W. G. Austin \& S. Worchel (Eds.), The social psychology of intergroup relations (33-47). Monterey, CA: Brooks/Cole.

Tebaldi, E. \& Elmslie, B. (2006). Sexual orientation and labor supply. Applied Economics, 38, 549-62.

Tsui, A. S., Egan, T. D. \& O’Reilly, C. A. (1992). Being different: Relational demography and organizational attachment. Administrative Science Quarterly, 37, 549-579.

Turner, J., Hogg, M. A., Oakes, P. J., Reicher, S. D. \& Wetherell, M. S. (1987). Rediscovering the social group: A self-categorization theory. Oxford, UK: B. Blackwell.

Van-Knippenberg, D., De-Drue, C. K. W. \& Homan, A. C. (2004). Work group diversity and group performance: An integrative model and research agenda. Journal of Applied Psychology, 89, 10081022.

Weaver, G. R. \& Agle, B. R. (2002). Religiosity and ethical behavior in organizations: A symbolic interactionist perspective. Academy of Management Review, 27, 77-97.

Weeks, M. \& Vincent, M. A. (2007). Using religious affiliation to spontaneously categorize others. The International Journal for the Psychology of Religion, 17, 317-331.

Weichselbaumer, D. (2003). Sexual orientation discrimination in hiring. Labor Economics, 10, 629-42.

Wesolowski, M. A. \& Mossholder, K. W. (1997). Relational demography in supervisor-subordinate dyads: Impact on subordinate job satisfaction, burnout, and perceived procedural justice. Journal of Organizational Behavior, 18, 351-362.

Whittington, J. L., Pitts, T. M., Kageler, W. V. \& Goodwin, V. L. (2005). Legacy leadership: The leadership wisdom of the Apostle Paul. The Leadership Quarterly, 16, 749-770. 